\title{
O Acolhimento como Estratégia de Diagnóstico e Intervenções Oportunas do Sofrimento Psíquico Entre Mulheres no Pré e Pós-Natal: Propostas de Intervenções em Enfermagem
}

\author{
Ramos, Ana Raquel Xavier; Silva, Liniker Scolfild R. da; Fonsêca, Jéssica Ramalho \\ da; Silva, Raymara Alves da; Correia, Nathália da Silva; Cordeiro, Eliana Lessa \\ Uninter — anaquelxr@hotmail.com
}

Introdução: a gestação e o puerpério são momentos da vida que envolvem inúmeras alterações físicas, hormonais, psíquicas e sociais. Os transtornos mentais acometem frequentemente as mulheres neste período de vulnerabilidade social e afetiva. Dentre estes agravos, as depressões pós-parto e as psicoses puerperais são alterações psíquicas dependentes de fatores orgânicos, familiares, conjugais, sociais, culturais e da personalidade da mulher que, quando presentes, causam prejuízos ao bem estar psíquico, seja na fase da gestação ou até mesmo no puerpério. Estes transtornos mentais podem ter implicações negativas na relação mãe-bebê e afetar o desenvolvimento da criança. a ocorrência dos agravos faz um alerta para a importância da intervenção de forma humanizada na assistência ao pré-natal e puerpério. Objetivo: Refletir as técnicas de acolhimento como estratégia de diagnóstico e intervenções oportunas para mulheres com sofrimento psíquico no pré e pós-natal. Método: Trata-se de um estudo descritivo, do tipo reflexivo, no qual busca-se estudar dentre as ações diagnósticas de enfermagem nos serviços de saúde no pré e pós natal, quanto a saúde mental da população feminina, a amostra será por conveniência, sendo composta por gestantes e puérperas, maiores de 18 anos, atendidas nos serviços de pré-natal e de puericultura de um ambulatório/maternidade de referência do estado de Pernambuco. como critério de exclusão não participarão desta pesquisa, mulheres menores de 18 anos, não gestantes, não puérperas, gestantes com ameaça de abortamento, mulheres portadoras de algum transtorno mental prévio e mulheres com deficiência auditiva. Instrumentos da pesquisa: questionário de levantamento de dados socioeconômicos, para análise de fatores biopsicossociais e o Questionário de Morbidade Psiquiátrica em Adultos - QMPA que é validado no Brasil com ponto de corte igual ou superior a 07 pontos como critérios de positividade. Resultados: Não há resultados ainda encontrados, pois a pesquisa encontra-se em fase inicial de aplicação do projeto piloto, uma vez que será submentida ao comitê de ética e pesquisa, seguindo para a plataforma Brasil. Conclusão: Tomando como base as diretrizes referentes aos cuidados no pré-natal e puerpério, é fundamental que o profissional de saúde possa munir-se de meios que garantam uma assistência humanizada, investigando aquilo que possa influenciar no processo saúde/doença. de posse de uma avaliação do perfil socioeconômico e através da aplicação do QMPA feito com cada gestante e puérpera, será possível identificar a presença de sofrimento psíquico nestas mulheres, que não raras vezes passam despercebidos, numa perspectiva futura de estar ajudando a melhorar a assistência à mulher. Consequentemente, o diagnóstico de adoecimento mental se tornará mais rápido, e quando necessário, a cliente será encaminhada para um atendimento mais específico, proporcionando assim uma gravidez mais segura para mãe e concepto.

Ramos, Ana Raquel Xavier; Silva, Liniker Scolfild R. da; Fonsêca, Jéssica Ramalho da; Silva, Raymara Alves da; Correia, Nathália da Silva; Cordeiro, Eliana Lessa. O Acolhimento como Estratégia de Diagnóstico e Intervenções Oportunas do Sofrimento Psíquico Entre Mulheres no Pré e Pós-Natal: Propostas de Intervenções em Enfermagem. In: Anais do Congresso Internacional de Humanidades \& Humanização em Saúde [= Blucher Medical Proceedings, num.2, vol.1]. São Paulo: Editora Blucher, 2014. ISSN 2357-7282 DOI 10.5151/medpro-cihhs- 10700 